se sentido, é importante destacar a contribuição fundamental deste livro quando confronta o discurso oficial, com base na análise das políticas educacionais de ambos os países, e a realidade escolar.

O objetivo do trabalho foi plenamente alcançado, pois a pertinência da abordagem metodológica, a abrangência do estudo e a análise realizada permitiram aprofundar a discussão sobre as trajetórias do ensino técnico e profissional e do ensino médio regular. Os autores conduziram a pesquisa respeitando a diversidade e a dimensão dos problemas de cada país, sem abrir mão da análise das políticas que têm estruturado historicamente esse nível de ensino. Além disso, os pesquisadores abordaram e buscaram interpretar "até que ponto se instalam, na prática, as possibilidades e as dificuldades de tais políticas educacionais", investigando, no cotidiano escolar, como se dá a formação dos alunos e quais "são os significados que os educadores responsáveis por esta formação atribuem a esta educação".

Em Portugal, foram realizados estudos de caso em cinco escolas localizadas em diferentes regiões do país, que apresentavam características distintas: algumas existentes há mais de cem anos; outras, construídas especificamente para o ensino profissional; outras, ainda, adaptadas recentemente

a esta modalidade de ensino. No Brasil, foram realizados três estudos de caso: um, em escola da rede de ensino do Estado de São Paulo, que oferece ensino técnico profissionalizante de nível médio, pertencente ao Centro Paula Sousa; o segundo, realizado em escola que oferece o ensino técnico profissionalizante de nível médio do Serviço Nacional de Aprendizagem Comercial - Senac -, que compõe o denominado sistema "S" de ensino profissional, finalmente, o terceiro, realizado em escola de ensino médio regular, nos períodos diurno e noturno.

O livro insere-se no debate que está posto sobre a complexidade de que se reveste a implementação das reformas do ensino médio em âmbito internacional e aponta, com mérito, questões que precisam ser aprofundadas em estudos posteriores, configurando-se, portanto, como leitura obrigatória para todos aqueles que tenham algum interesse em realizar pesquisas sobre o tema.

$$
\begin{array}{r}
\text { Angela Maria Martins } \\
\text { Programa de Mestrado em Educação da } \\
\text { Universidade Católica de Santos e } \\
\text { Departamento de Pesquisas Educacionais da } \\
\text { Fundação Carlos Chagas } \\
\text { amartins@fcc.org.br }
\end{array}
$$

\section{QUALIFICAÇÃO PROFISSIONAL: UMA TAREFA DE SÍSIFO}

Claudia Mattos Kober

Campinas: Autores Associados, 2004,

O livro de Claudia Mattos Kober tem como objetivo implícito a desconstrução do consenso que vincula linearmente educação, qualificação, emprego e desenvolvimento. Ou seja, procura desmitificar a idéia de que, quanto mais educado e qualificado for um indivíduo, maiores serão os retornos, não só em termos pessoais - maiores chances de inserir-se e se recolocar no mercado de trabalho (de tornar-se "empregável", para usar o jargão atual), de receber aumentos salariais, promoção etc. -, como também sociais: aumentar a produtividade das empresas e, conseqüentemente, gerar desenvolvimento econômico e social para os países. Apesar de essa idéia não ser nova - a teoria do capital humano, já a defendia nos anos 60 -, a força que ela adquire na atualidade, em um contexto de acirrada competição devido às altas 
taxas de desemprego, faz com que as determinações econômicas e sociais desse fenômeno sejam transferidas aos indivíduos, que passam a ser cada vez mais responsabilizados por seu destino pessoal.

Tendo sido convidada para montar um programa de treinamento para trabalhadores de uma multinacional, dentro de uma nova perspectiva de organização do trabalho, Kober acompanhou de perto a força desse discurso, ao ver inúmeros trabalhadores retomarem os estudos abandonados há muito tempo, sempre com a esperança de se manterem empregados ou de conquistarem um novo emprego. Na verdade, vários estudos já foram realizados, tanto na área da educação quanto na do trabalho, para mostrar a fragilidade dessa relação de causa e efeito. Da mesma forma, também já é clássica a recusa da linearidade entre inovações tecnológicas e maior escolaridade, uma vez que a mesma tecnologia pode ser acompanhada de práticas diferenciadas quanto à seleção e designação aos novos postos de trabalho. Ao ver, porém, o quanto essa "tarefa de qualificar-se" era "árdua e complicada", Kober resolveu pesquisar como os sujeitos vivenciavam o que denomina "uma forma sofisticada de violência simbólica" (p.|4I). Essa é a originalidade de sua dissertação de mestrado, agora transformada em livro.

Se a tese implícita não é, portanto, nova, o livro de Kober tem o mérito de mostrar como alguns trabalhadores de linhas de produção da indústria compreendem sua qualificação profissional, o modo pelo qual ela foi construída ao longo de sua história de vida, as novas exigências que pesam sobre ela, e como articulam as esferas da família, da escola e do próprio trabalho nas decisões e práticas a respeito da qualificação e da requalificação. Estes são os objetivos da autora. Sua premissa é a de que a percepção e a vivência do indivíduo são frutos de suas relações com diversas instâncias sociais (família, escola, trabalho, igreja, sindicato etc.) e, simultaneamente, guiam novas escolhas, estratégias e práticas que darão origem a novas relações.
No primeiro capítulo, a autora desenvolve o aparato teórico-metodológico necessário para levar a cabo seu trabalho de campo. Analisa como as transformações econômicas, políticas e sociais das últimas décadas, que envolvem desde uma nova forma de acumulação do capital e de organização e gestão do trabalho até uma nova forma de ser e de trabalhar - o que tem sido associado à substituição do conceito de qualificação pela noção de competência -, fortalecem a idéia que vincula educação-qualificação-emprego.

Como a noção de competência é um atributo que remete à subjetividade do indivíduo e se relaciona com a sua capacidade de mobilizar saberes e atitudes para, de forma autônoma, resolver problemas, ela "e sua correlata, a noção de empregabilidade, acabam por abstrair relações sociais muito mais complexas do que se supõe" (p.32) "e o que sobra é a culpabilização individual por tragédias individuais" (p.35). Se o objeto de Kober é a qualificação profissional, a autora não pôde deixar de contrapô-la à competência, que tem sido globalizada para os mais diversos contextos societais, designando novas configurações nas práticas sociais. Entretanto, como bem esclarece, a difusão dessa noção e o "modelo" de gestão do trabalho a ela associado tiveram origem nos países centrais e fazem sentido nas grandes empresas que empregam mão-de-obra basicamente masculina. Dito de outra forma, esse "modelo" não se aplica a todos os trabalhadores da mesma maneira, principalmente se são consideradas dimensões da divisão internacional e sexual do trabalho, da etnia, etc. No Brasil, em que nem mesmo a qualificação adquiriu o peso social que teve nos países centrais, principalmente na França - onde, por meio de acordos coletivos, as qualificações foram transformadas em um sistema de classificações profissionais que definiam as regras para reger a trajetória profissional dos assalariados -, o debate em torno da noção de competência parece deslocado.

Mas o fato é que o discurso da competência chega até nós, tanto na esfera da educação 
como na do trabalho, e Kober ratifica a crítica que muitos autores fazem a ela: apesar de vir sempre relacionada a fatores muito positivos democracia, cidadania e justiça social na área educacional e autonomia, participação e iniciativa no âmbito do trabalho -, não se pode esquecer que essa noção é gestada "no interior de mudanças socioeconômicas ligadas à organização da reprodução e acumulação do capital, agora no seu modo financeiro, sendo, portanto, impregnada da lógica dos valores do mercado, em consonância com sua origem empresarial" (p.33).

Ainda que a crítica faça sentido, faltam dados para mostrar que "essa lógica está sendo transportada para a escola", como sugere a autora. Em outras palavras, tem-se a impressão de que ela faz a crítica da competência a partir do mundo do trabalho, que, por mais que influencie e tenha semeIhanças com a esfera da educação, também tem suas particularidades. No campo educacional, não se deve esquecer que a noção de competência já era discutida pelas ciências da cognição muito antes de ser apropriada pelas empresas. Assim, se a crítica aos pressupostos de um ensino centrado nas competências é pertinente, não é ainda possível prever seus efeitos, o que demanda muito tempo e várias pesquisas, pois se sabe que não há uma relação direta e unívoca entre mercado e escola. Da mesma forma, a afirmação de que a lógica da competência favorece "a individualização das negociações salariais e de condições de trabalho, enfraquecendo as negociações coletivas" (p.33), ressente-se de uma análise mais precisa das mediações dessa prática e de como ela reverte no mercado de trabalho do país, pois, como reconhece a própria autora, "nosso crescimento industrial deu-se contando com uma mão-de-obra abundante, de baixa qualificação e barata [e], talvez por isso, quando olhamos o mercado de trabalho brasileiro, essa discussão [sobre a competência] provoque profunda estranheza" (p.30).

De qualquer modo, Kober recusa a noção de competência e mantém a concepção de quali- ficação como construção/relação social: "a qualificação dos trabalhadores se dá por meio da articulação entre a sua subjetividade e o modo como ela é intrinsecamente vinculada às relações sociais, ao conjunto dos trabalhadores e ao modo de reprodução do capital" (p.36). Em contrapartida, se a qualificação é uma construção/relação social, é também porque - e isso não está explícito no argumento teórico da autora - ela se remete às operações realizadas para classificar e hierarquizar os indivíduos e os empregos em matéria de conhecimentos exigidos, de salários e de prestígio. As competências formadas pela escola - mas não só por ela - só se tornam qualificação quando são reconhecidas socialmente. A qualificação assim concebida é, pois, muito mais ampla do que a escolaridade e a competência. No entanto, em alguns momentos, Kober parece associá-la apenas ao ensino formal: se ela é construída, é problemático afirmar que nossa mão-de-obra era de "baixa qualificação" (p.30). Ainda que esta seja uma idéia corrente, seria importante questioná-la, já que a autora se empenha em desconstruir consensos estabelecidos. A pergunta aqui é: baixa qualificação em termos de escolaridade e formação ou de condições de trabalho? Ou de ambos? Além disso, quando se refere à idéia que vincula educação, qualificação e emprego, algumas vezes Kober utiliza indistintamente os dois primeiros termos.

A mesma naturalização ocorre com a caracterização de seus entrevistados, dois grupos de trabalhadores de linha de produção, que tinham em comum a volta ao ensino supletivo: o primeiro, formado por sete trabalhadores que cursavam o supletivo do ensino fundamental em uma escola municipal e trabalhavam em diversas empresas tradicionais; o segundo, por oito sujeitos que estavam no ensino médio dentro da indústria em que trabalhavam, a qual havia passado por processo de reestruturação produtiva. Em algum outro momento, a autora afirma que entrevistou trabalhadores de "baixa qualificação" (“...mesmo entre trabalhadores pouco qualifica- 
dos, como os entrevistados...", p.62), como se o fato de eles realizarem suas funções na linha de produção indicasse, de per si, essa caracterização. Aqui, seria não só produtivo esclarecer por que era essencial entrevistar essa categoria de trabalhadores, como, também, importante acrescentar "considerados pouco qualificados", já que Kober diz tomar a qualificação como uma construção/relação social.

Apesar das lacunas percebidas, o desenvolvimento e a análise da pesquisa propriamente dita nos capítulos subseqüentes são primorosos. Para compreender as percepções e opções dos trabalhadores quanto à sua qualificação, Kober se utiliza do referencial teórico de Bourdieu, especialmente das noções de espaço social e habitus. Construído em relação com as estruturas objetivas que condicionam a posição do indivíduo dentro do espaço social, mas, ao mesmo tempo, articulado com a história e as ações do indivíduo, o habitus é constantemente reconstruído. A noção de habitus permite, portanto, a mediação das condições objetivas e das práticas operadas no cotidiano. Como a família, a escola e o trabalho são o locus privilegiado para a constituição do habitus, é neles que a autora se concentra, para compreender como essas instâncias sociais passadas e presentes - estruturas objetivas - são percebidas pelo trabalhador e como este as articula com suas ações a respeito da qualificação.

Com um estilo claro, agradável e envolvente, Kober conta-nos que, na história de vida da maioria dos entrevistados, escola e trabalho foram opções excludentes ou estiveram articulados desde muito cedo. No presente, todos os sujeitos da amostra voltaram aos bancos escolares e tal decisão difere um pouco entre os dois grupos entrevistados: enquanto o primeiro, com um nível de escolaridade mais baixo, tem "vontade de estudar" e busca mais conhecimentos (especialmente aqueles básicos de leitura e escrita) - e a aquisição dessas habilidades é a contribuição que reconhecem da escola no dia-a-dia do trabalho -, a decisão do segundo está principalmente relacionada ao trabalho - e, para este grupo, que já detém as habilidades básicas, a escola não ajuda tanto na transmissão de conhecimentos, mas, antes, na formação de atitudes necessárias ao novo tipo de atividade que realizam.

De qualquer forma, todos eles, independentemente de trabalharem nos moldes tradicionais ou flexibilizados, estabelecem uma relação credencialista com a escola: associam linearmente educação e emprego, ou seja, acreditam que a escolaridade é fundamental para a inserção no mercado de trabalho ou para continuar na mesma empresa e, talvez, conseguir uma promoção. É também com base nessa percepção que o trabalhador se candidata a cursos de formação profissional fora da escola, promovidos pelo Estado, por Organizações Não Governamentais ONGs - ou pela própria empresa. Mas, em meio a tantas possibilidades, ele tem que escolher, sozinho, a melhor opção a seguir, e corre o risco de ver seu diploma desvalorizado, já que as empresas não necessariamente reconhecem essa forma de qualificação e tendem a valorizar seus próprios canais de treinamento.

Assim, para os entrevistados, a relação escola-trabalho "implica uma dose enorme de esforço e dedicação [...] depois (ou antes) de uma jornada de oito horas de trabalho pesado" (p.93). A alusão à figura da mitologia grega, no título do livro - Sísifo foi condenado por Zeus a carregar uma pedra até o alto de um morro, do qual ela sempre rolava novamente -, expressa justamente esse sacrifício pessoal para se educar e se qualificar continuamente, sem que isso necessariamente se transforme em garantia de emprego e inserção social; mais ainda, mesmo que se qualifiquem, os indivíduos continuam sendo responsabilizados pelo seu possível fracasso.

Por outro lado, ao analisar as articulações que seus entrevistados estabelecem entre família, escola e trabalho, Kober mostra que eles também sabem que, mesmo com maior formação, suas 
oportunidades serão limitadas em razão de condições objetivas. Nas suas palavras, "elementos que se combinam para que um trabalhador se dê bem profissionalmente não se restringem, porém, para os entrevistados, àqueles de algum modo pertencentes ao indivíduo, tais como escolaridade e características pessoais. Alguns desses elementos são intrínsecos ao trabaIho propriamente dito e à empresa contratante, bem como à qualidade do trabalho executado" (p. I I I).

Para a autora, isso significa que a percepção desses sujeitos aproxima-se da noção de qualificação como construção/relação social.

Sendo assim, sua pesquisa contraria o discurso da culpabilização individual, pelo qual os indivíduos se auto-responsabilizariam pelo seu destino pessoal, obscurecendo os condicionantes sociais objetivos. Se Kober aponta diversas pesquisas que mostram que os sujeitos têm atribuído o desemprego à falta de qualificação dos trabalha- dores - o que, na maioria das vezes, significa falta de credenciais escolares e/ou qualidades pessoais -, seus entrevistados parecem ter uma visão diferente a respeito do fenômeno, já que compreendem que o processo de qualificação "não depende apenas da escola e nem apenas do trabalhador" (p. I 44), mas também do seu reconhecimento por parte da empresa e das condições de trabalho que ela oferece. Essa diferença entre seu pressuposto e a realidade encontrada poderia ter sido mais bem explicitada, pois valorizaria os resultados da pesquisa. De toda forma, trata-se de um texto estimulante, cuja leitura é recomendada àqueles que se interessam pelas relações entre educação e trabalho.

Gisela Lobo B.P.Tartuce

Departamento de Pesquisas Educacionais da Fundação Carlos Chagas gtartuce@fcc.org.br

\section{PLURALIDADE CULTURAL E INCLUSÃO NA FORMAÇÃO DE PROFESSORAS E PROFESSORES: GÊNERO, SEXUALIDADE, RAÇA, EDUCAÇÃO ESPECIAL, EDUCAÇÃO INDÍGENA, EDUCAÇÃO DE JOVENS E ADULTOS}

\author{
Margareth Diniz e Renata Nunes \\ Vasconcelos (orgs.)
}

Belo Horizonte: Formato, 2004, I87p.

(Série Educador em Formação)

Os estudos sobre currículo têm indicado a necessidade premente de se repensar a formação dos professores no sentido de possibilitar-lhes maior contato com os subsídios que movimentam o debate curricular atual. Entende-se que os professores não apenas aplicam, mas reinterpretam as diretrizes curriculares que lhes são apresentadas a partir de suas próprias leituras de mundo e que, por isso, precisam refletir coletivamente sobre sua prática, de forma a desenvolverem consistentemente tanto o ensino como a si mesmos como profissionais.

Quando o que se busca é a oferta de uma escola que respeite as diferenças, a preocupação com a prática docente se acentua, pois o preconceito e a segregação ocorrem, no mais das vezes, de maneira sutil no cotidiano escolar. Lidar com as diferenças "exige sensibilidade diante de qualquer discriminação no trato cotidiano, evitando que os próprios docentes sejam a fonte de juízos, atitu- 